\title{
SEISMIC ASSESSMENT OF A RC CASE STUDY BUILDING USING THE SIMPLE LATERAL MECHANISM ANALYSIS, SLAMA, METHOD
}

\author{
Roberto Gentile $^{1}$, Ciro Del Vecchio ${ }^{2}$, Giuseppina Uva ${ }^{1}$, and Stefano Pampanin ${ }^{3}$ \\ ${ }^{1}$ Dipartimento di Ingegneria Civile, Ambientale, del Territorio, Edile e di Chimica, Politecnico di Bari \\ via Edoardo Orabona, 4, 70126 Bari, Italy \\ e-mail: roberto.gentile@poliba.it; giuseppina.uva@poliba.it \\ ${ }^{2}$ Department of Structures for Engineering and Architecture, University of Napoli "Federico II", \\ via Claudio 21, 80125, Napoli, Italy \\ ciro.delvecchio@unina.it \\ ${ }^{3}$ Department of Civil and Natural Resources Engineering, University of Canterbury, \\ Christchurch, New Zealand \\ stefano.pampanin@,canterbury.ac.nz \\ ${ }^{3}$ Department of Structural and Geotechnical Engineering, Sapienza University of Rome, \\ Via Eudossiana 18, Rome, Italy \\ stefano.pampanin@unroma1.it
}

Keywords: Seismic assessment; SLaMA; displacement-based; simplified tool; pushover.

\begin{abstract}
The seismic assessment of an existing structure is a complex procedure. In the evaluation of the structural capacity, difficulties arise in the definition of the lateral resisting members, in the estimation of the lateral capacity from component to system level. The identification of the local and global mechanisms, depending on the hierarchy of strength at subassembly level, is a challenging task. Nowadays, advanced numerical analysis procedures, implemented in user-friendly commercial software, are commonly adopted in the current practice to overcome the difficulties in the use of non-linear analyses. Nevertheless, their accuracy strongly depends on the ability of the numerical model to capture all the probable failure mechanisms. To help the user in the assessment of the probable failure mechanism and to have a first estimation of the building lateral capacity, the Simple Lateral Mechanism Analysis (SLaMA) method has been recently developed and included in the NZSEE 2016 guidelines. SLaMA is a simple and reliable "by-hand" tool to derive the local and global mechanism of a structural system and the corresponding capacity curve. This paper deals with the application of the SLaMA to an existing RC building severely damaged during the Christchurch earthquake (2011, New Zealand). The lateral capacity of four 2D resisting systems was assessed following the SLaMA method. The results of a refined nonlinear numerical model were used to assess the accuracy and reliability of SLaMA. The good match confirmed that SLaMA can be a useful and simple tool to have a first estimation of the building lateral response. It allows to identify the main structural weaknesses driving the user to the development of more refined nonlinear models.
\end{abstract}




\section{INTRODUCTION}

High uncertainties characterize the seismic assessment procedures both at building and regional level [1]. Although significant advances were made to improve the procedures for the input selection and in the development of refined analysis methods, difficulties are still present. Nowadays, thanks to user-friendly commercial software, the use of non-linear analyses is common in the design practise. It is worth mentioning that, although the non-linear analysis are the most refined tools for the seismic assessment of existing buildings, their accuracy strongly depends on the ability of the numerical model to capture all the probable failure mechanisms.

For existing RC structures, characterising the lateral capacity of existing members (beams, columns, walls) that do not conform to modern seismic codes is challenging. This is because the lack of seismic detailing may lead to different failure mechanisms (flexure, shear, bar buckling, slip at the lap-splice of longitudinal reinforcement). Moreover, the lack of seismic detailing may have detrimental effects on the seismic capacity of beam-column joints. Indeed, recent earthquakes and relevant scientific studies ([7], [8]) outlined that the shear failure of poorly detailed beam-column joints significantly affects the structural seismic performances. High uncertainties are also related to the estimation of the probable material properties and to the influence of stiff-infill on the structural behaviour ([2], [3], [4], [5], [6]). As a result, the development of reliable numerical models to be employed in refined non-linear analysis is of paramount importance and the designers should have the chance to check the model accuracy. Nevertheless, the lack of simple tools to quickly assess the model accuracy or the influence of the modelling assumptions on the strength hierarchy, the failure mechanism and the global capacity curve makes the entire assessment procedure susceptible to large errors. In order to help the designers in the development of reliable nonlinear models, a step-by-step simplified analysis method named Simple Lateral Mechanism Analysis (SLaMA) was recently proposed in the New Zealand Society for Earthquake Engineering, NZSEE2016, guidelines for Detailed Seismic Assessment (DSA) of existing building [11]. As reported in the document: "The onus is on the assessing engineer to understand the level of reliability available from the chosen assessment approach and to be able to articulate this to the end user of the DSA".

In this paper, SLaMA is used to predict the lateral capacity of 2D lateral resisting systems extracted from a real building damaged by the 2011 Christchurch earthquake. In particular, the SLaMA method, which can be referred to as a "by-hand analytical pushover", is proposed as a reliable benchmark to assess the accuracy of a numerical model/analysis of a RC structure in predicting the main structural weaknesses and the capacity curve itself.

\section{RESEARCH METHODOLOGY}

A RC case study building damaged by the Christchurch earthquake (New Zealand, 2011) was selected for this study. The response of its main lateral resisting systems was assessed using both SLaMA and 2D refined nonlinear numerical models by using the FEM software Ruaumoko [12]. All the structural nonlinearities typical of the "non-conforming" RC structures, i.e. flexural-shear interaction, bar buckling, joint shear failure, possibility of soft-storey mechanisms, were properly considered. The results of the numerical model are directly compared with those predicted with SLaMA. The non-linear capacity curves and the plastic mechanism predicted at the ultimate limit state are compared and discussed.

The capability of SLaMA of predicting the actual hierarchy of strength and, hence, the plastic mechanism obtained from refined numerical pushover analyses is discussed. This confirmed that this simplified method can be used to have benchmark capacity curves useful to check the accuracy of refined numerical models. 


\section{CASE STUDY BUILDING}

The case study building is an 8 -storey RC building (approx. $24 \mathrm{~m}$ tall) which was used as commercial office before the February 2011 Canterbury earthquake. It was built in 1974 and designed according to pre-70's practice when capacity design and seismic detailing were not yet introduced. The building was part of a reconnaissance project developed in the aftermath of the abovementioned earthquake and hence the observed damage state can be found in [13], [14].

Figure 1 shows the plan view of the ground level, taken from the original structural drawings, and the idealisation of the structure. The structural system consists of RC perimeter frames and a C-shaped structural wall, which is also connected to the corner columns through link beams, forming a frame-wall system. Assuming a decoupled behaviour of the web and the flanges of the C-wall, for the purpose of this work, the lateral resisting systems "extracted" from the building (see Figure 2) are the following:

- Frame 1: the RC frame on gridline 1 (N-S or y-direction);

- Frame A: the RC perimeter frame on gridline A, (E-W or x-direction). This is identical to the frame on gridline $\mathrm{D}$;

- Wall (flange only): two flanges of the RC C-shaped wall on the east side of the building;

- Dual System: the RC frame-wall system formed by the web of the C-wall connected to the corner columns through link beams (y-direction).

Building geometry, material properties, members dimensions, reinforcement detailing, load analysis and photographic report of the damage are widely discussed in [15] and [14].

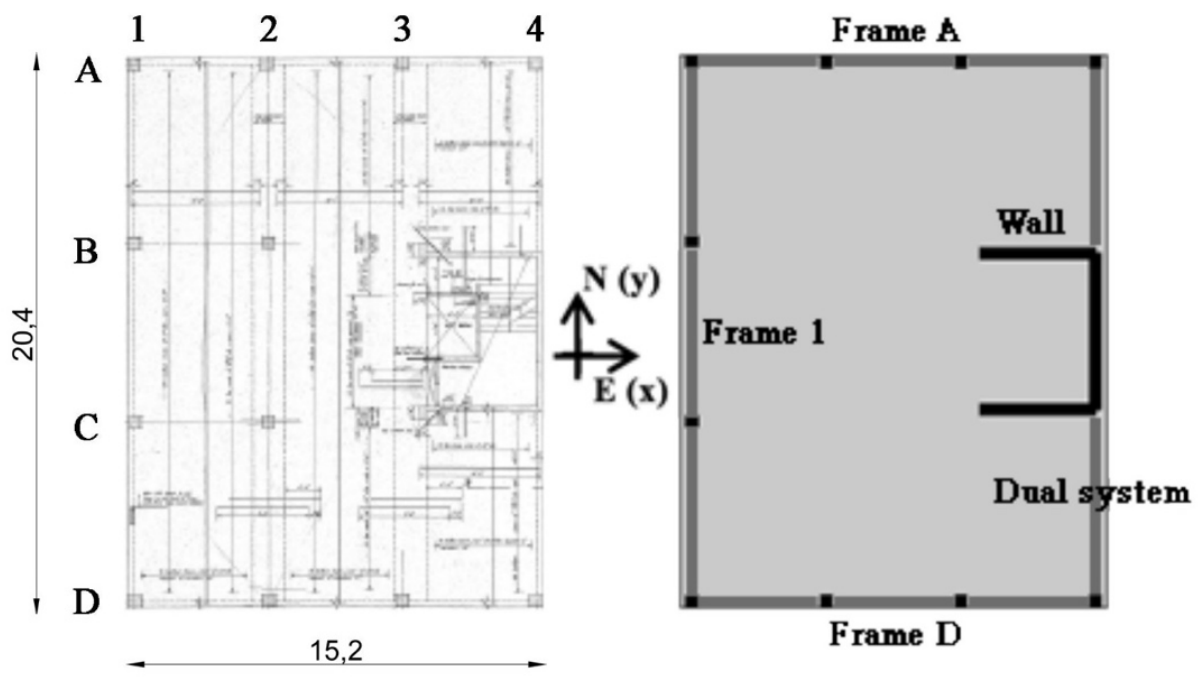

Figure 1: Original plan view of the ground level and idealisation of the structural system.

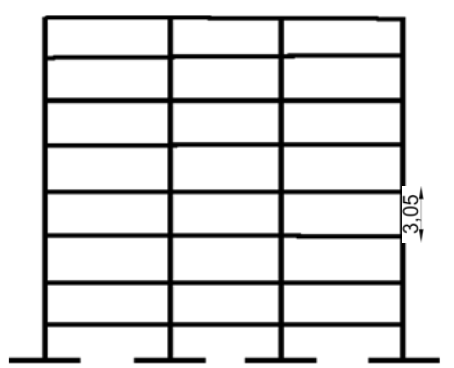

Frame 1 - Frame A/D

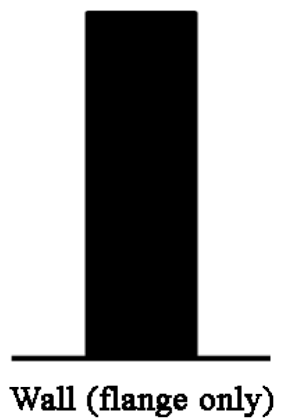

Wall (flange only)

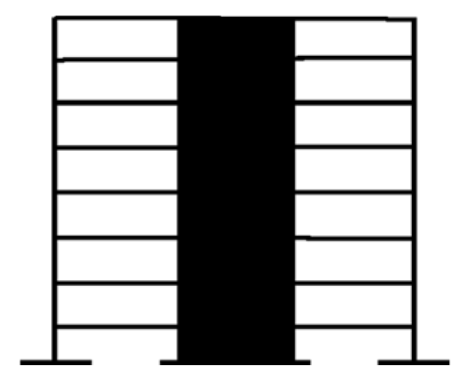

Dual system

Figure 2: Schematic of the structural systems of the case study building. 


\section{SIMPLE LATERAL MECHANISM ANALYSIS}

\subsection{The method}

The Simple Lateral Mechanism Analysis, introduced in the New Zealand code in 2006 [11] and significantly improved in the 2016 [24] version, can be referred to as a "by-hand analytical pushover" in which the structure capacity curve is calculated using basic principles. In line with the Direct Displacement Based Assessment (DDBA) approach, this method is a powerful instrument to assess the seismic performance (capacity-to-demand ratio in the ADRS domain) of relatively complex structures also considering 3D effects (inelastic torsion).

This paper deals with the application to 2D lateral resisting systems (see Figure 3Figure 4). A full example of the application of SLaMA, including detailed calculations and 3D effects is reported in detail in Del Vecchio et al. [15].

The starting point of the SLaMA method is the characterisation of the lateral capacity of each of the structural member (beams, columns, joints, walls) performing software-based sectional analyses (e.g. [18]) or by-hand simplified calculations. It is worth noting that this process would be carried out, in an identical way, to characterise the nonlinearities of a lumped plasticity numerical model. To avoid repetition, the details on this aspect are given in Section 5, when discussing the numerical models assumptions. The interaction between the members in each beam column joint subassembly is analysed (hierarchy of strength calculation, [25], see Figure 3 ). These results allow to assess the probable inelastic mechanism of the structure and calculate the related strength using equilibrium conditions. It is worth noting that, in order to compute the base shear strength, a full redistribution of the actions is assumed. Indeed, the fully exploit of the strength capacity of all the beam-column subassemblies is considered. The displacement capacity at the effective height, representative of the SDOF system, is calculated multiplying the minimum drift capacity of the RC members experiencing the first yielding or the ultimate failure by the effective height (which depends on the probable inelastic mechanism, see Figure 4). In this paper, the SLaMA is discussed with reference to Frame A, while the principles of the method is explained in details in the NZSEE guidelines [24] and applied on a worked example in Del Vecchio et al. [15].
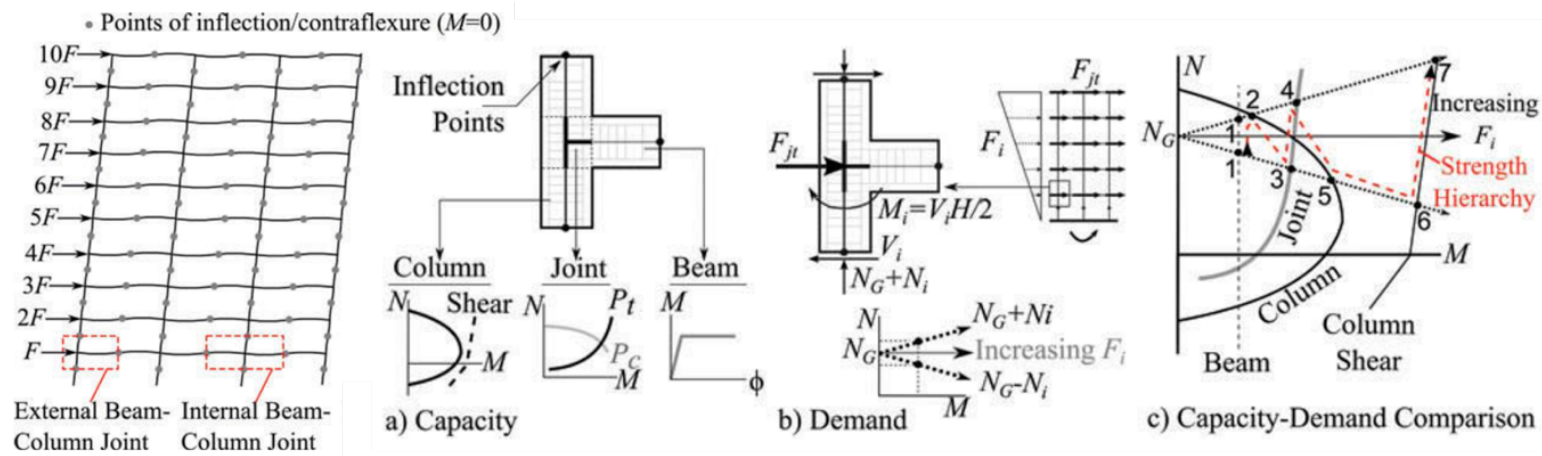

c) Capacity-Demand Comparison

Figure 3: SLaMA application for a frame structure (Pampanin et al., 2002; Tasligedik et al., 2016). 


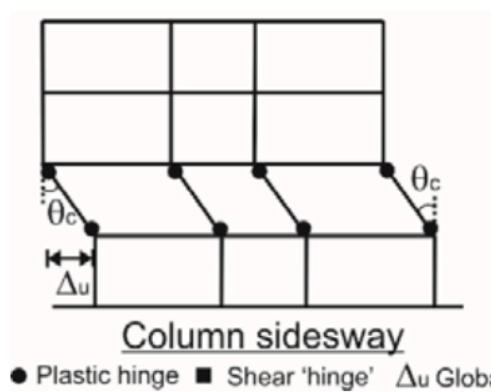

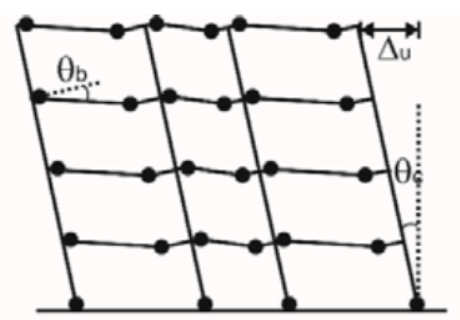

Beam sidesway

$\theta_{\mathrm{b}}$ Beam hinge rotation

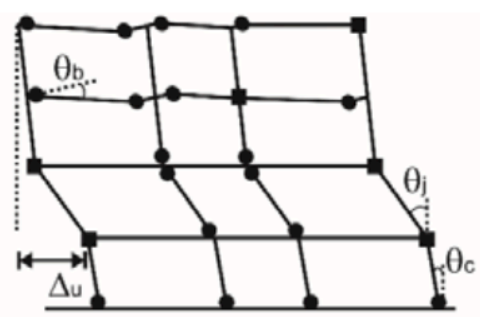

Mixed sidesway

Figure 4: Possible plastic mechanisms (NZSEE 2016).

\subsection{Results}

The lateral resisting systems (LRSs) individuated in Section 3 were analysed using SLaMA, predicting both the capacity curve and the plastic mechanism at the ultimate limit state. It is worth noting that, considering the predicted plastic mechanisms, for all the LRSs the effective height was considered to be two thirds of the total height of the building.

Taking frame A as example, Figure 5 shows the derivation of its plastic mechanism based on the hierarchy of strength of the beam-column-joint subassemblies. The numerical analysisbased mechanism is also shown to avoid duplications, although it is discussed in Section 6. The results show that the predicted plastic mechanism is a beam sway, characterised by beam hinges in all the subassemblies. However, for a significant number of them, as for example joint D1 shown in Figure 5, the beam plastic hinge is predicted after the joint first shear cracking. The next mechanism in the hierarchy, the joint failure, cannot develop because of the limited beam hardening.

Although the first cracking in the joints does not influence the base shear capacity of the frame, it increases its deformability. For this reason, the capacity curve (Figure 6) was computed twice: first characterising the yield displacement considering the beam hinging and then considering the joint deformability at peak strength. The second curve is considered for the comparison in Section 6, since it is deemed to yield a more conservative estimation of the lateral capacity.

The capacity curve for the other analysed lateral resisting systems is shown in Figure 10 (in Section 6) in the context of the comparison with the numerical analyses results.

\section{NUMERICAL ANALYSES AND NUMERICAL-ANALYTICAL COMPARISONS}

\subsection{Numerical modelling assumptions}

A 2D numerical model was developed using the FEM software Ruaumoko [12] for each lateral resisting system. A displacement-control Pushover was carried out imposing a linear lateral force profile and neglecting P-delta effects. Figure 7 summarises the modelling assumptions and the nonlinear behaviour of structural components. A lumped plasticity approach was adopted using a Giberson one-component model for the frame elements [16] that concentrates the members nonlinearities at the end sections of beams and columns. Several studies ([7], [8], [9]) highlighted the importance of modelling the non-linear behaviour of poorly-detailed beamcolumn joints. For this reason, in this study they were modelled by means of rotational springs connecting the beam and column elements that converge in one node. The characterisation of the nonlinearities was based on the geometry, material and reinforcement details of the members reported in the original drawings. 


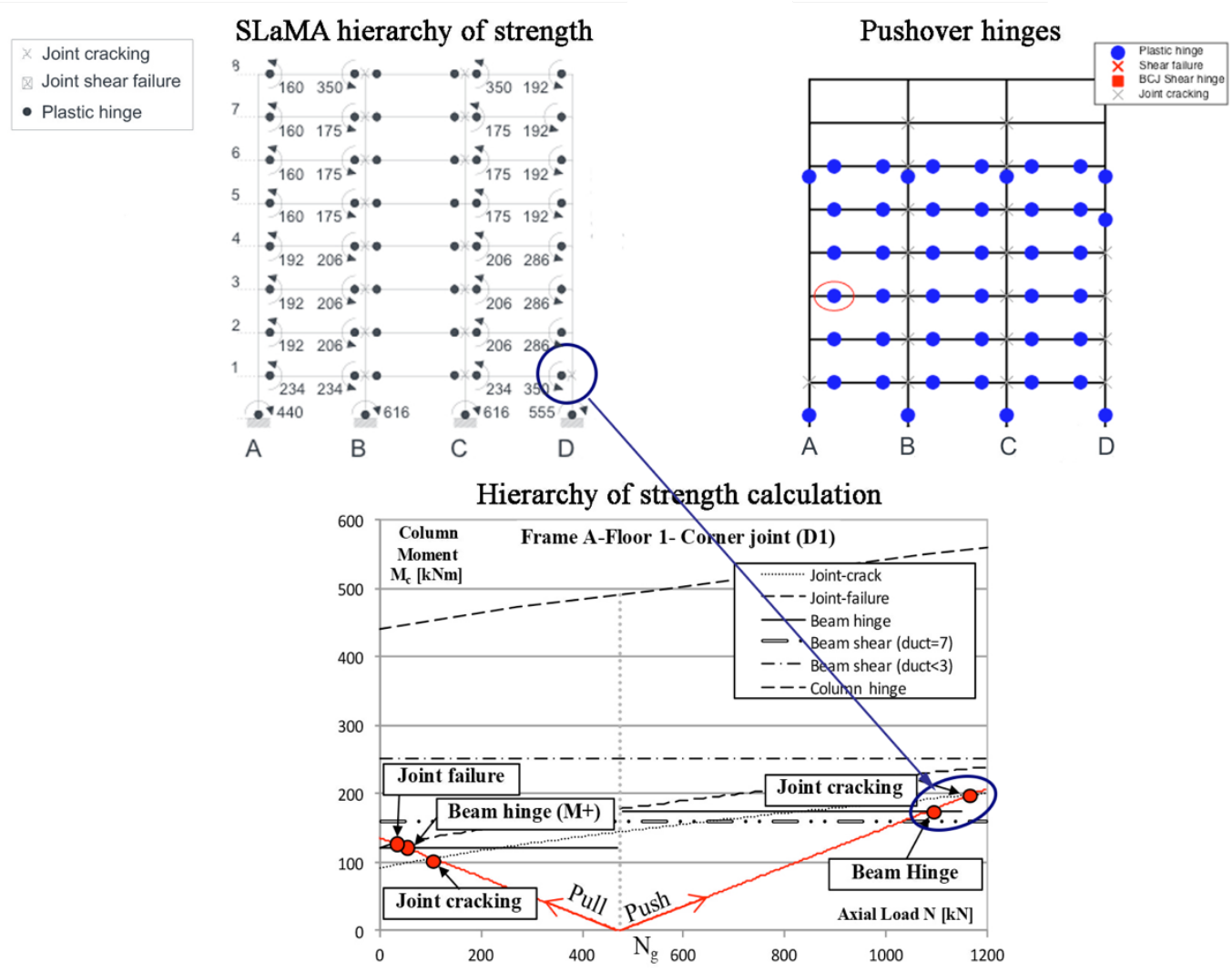

Figure 5: Plastic mechanism for frame A predicted through SLaMA and numerical pushover. On the bottom: hierarchy of strength of joint D1.

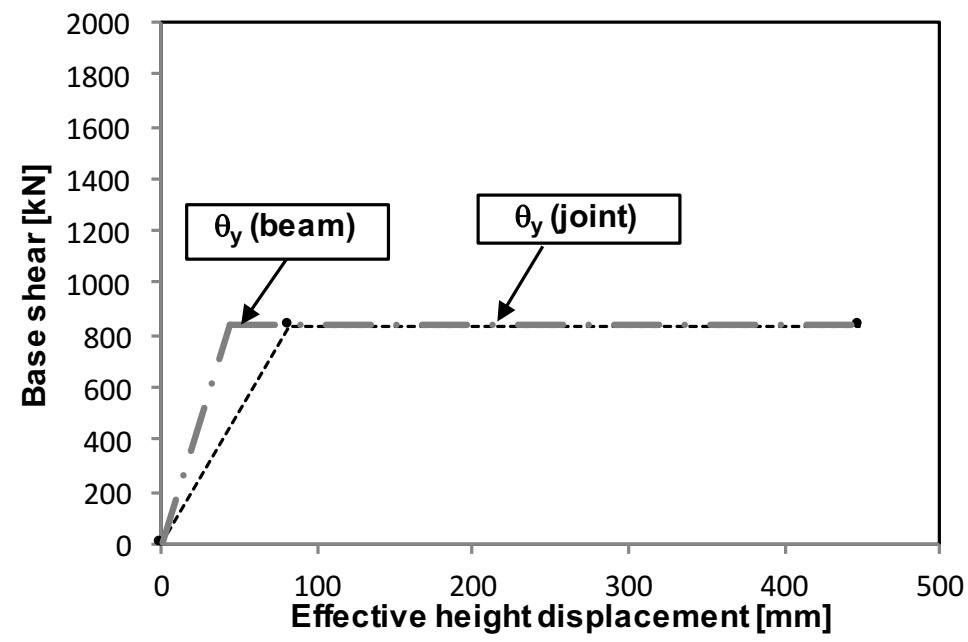

Figure 6: SLaMA capacity curve for Frame A.

In particular, the beams nonlinear behaviour was characterised basing on the equivalent plastic hinge length [17] and a bi-linear representation of the Moment-Curvature relationship calculated using the software CUMBIA [18] considering refined stress-strain relationships for concrete [19] and steel [20]. The approach proposed by Berry et al., 2005 [21] was used to check the buckling of the longitudinal bars. Finally, the shear degradation curve proposed by Kowalski and Priestley 2000 [22] was used to assess the possible shear failure limiting the drift capacity.

For columns, the same approach of beams was adopted, but in order to account for the influence of axial load on the moment capacity at different step of the analysis, the moment-axial 
load interaction diagram was used. A similar approach was adopted for walls, for which the shear degradation curve proposed by Krolicki et al., 2011 [23] was adopted. Finally, the joints capacity was calibrated basing on a principal stress approach that allows to define the strength of the joint panel at the first cracking and at a severe damage limit state in terms of equivalent moment in the column (more details on the method are given in Pampanin et al., 2003 [8], together with the adopted deformation limit states). The joints rotational springs are hence modelled by means of equivalent column moment - axial load interaction diagram, which allows to capture the variation of strength with the axial load on the joint panel, defined for first cracking and severe damage limit states.
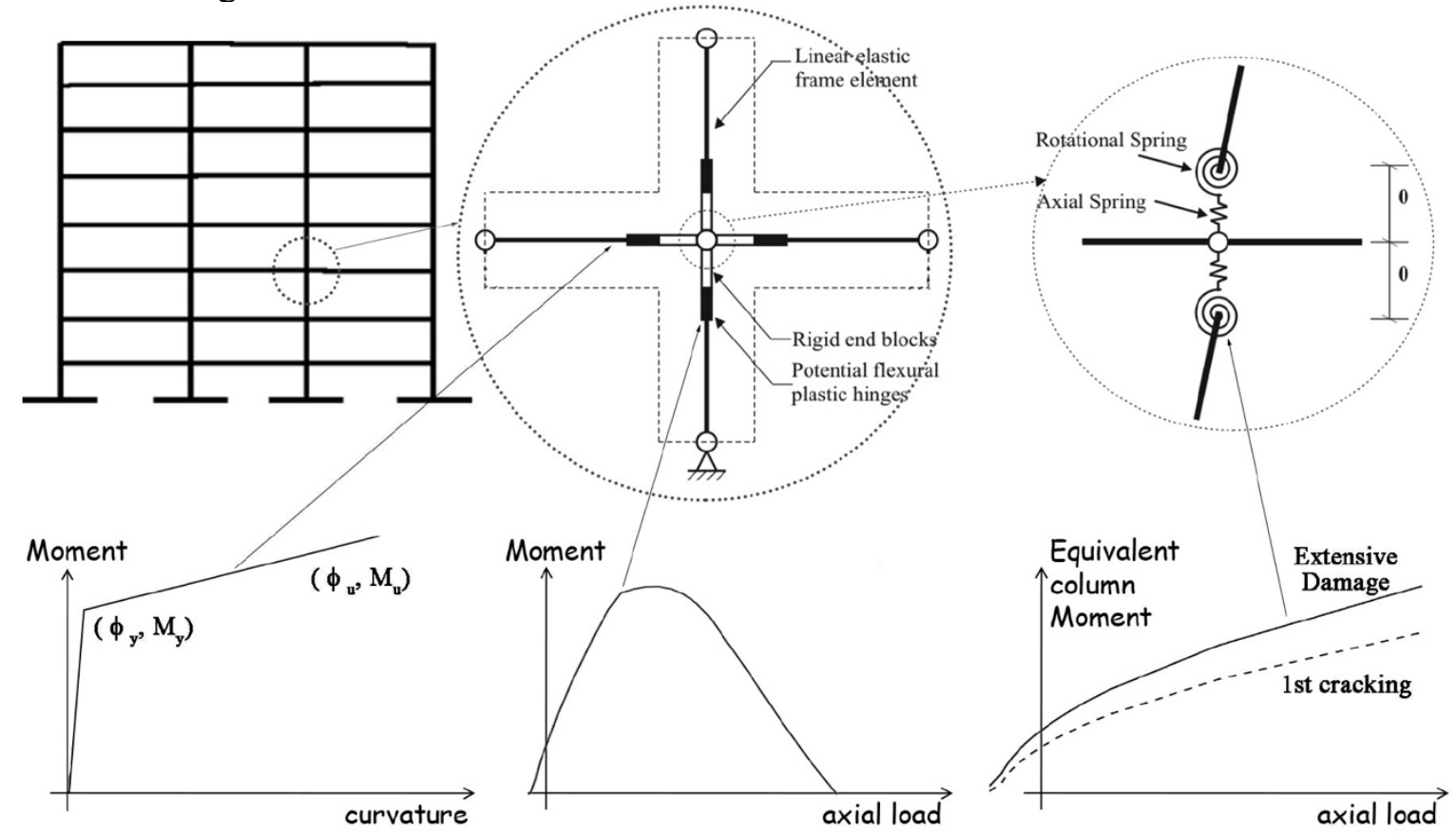

Figure 7: Numerical modelling assumptions and characterisation of the structural members.

\subsection{Results}

The capacity curves resulting from the pushover analyses, shown in Figure 8, are expressed in terms of base shear versus displacement at the effective height of the structural system (the adopted values for the effective height are discussed in Section 4.2) in order to represent the behaviour of an equivalent SDOF system. The ultimate point of the curves represents the step of the analyses in which the first member in the structural system reached its deformation capacity. A more detailed discussion on the numerical capacity curves is given in Section 6, in the context of the comparison with SLaMA. A snapshot of the formed hinges at the ultimate point is given in Figure 9, in which the members ductility demand is indicated and the member causing the ultimate limit state is highlighted with a circle. For the two frames, this indicates that the non-linear behaviour of the members is triggered up to the $6^{\text {th }}$ level, avoiding the formation of a global mechanism and not allowing for the full redistribution of the internal actions. This phenomenon is detrimental for the base shear capacity of the two systems. Frame 1 plastic mechanism is characterised by a combination of beam hinges and shear failure in the joints (Mixed Sidesway) while mainly beam hinges form in frame A (Beam Sidesway). A Mixed Sidesway mechanism with full redistribution forms in the dual system while the flange of the $\mathrm{C}$-wall is characterised by a flexural failure at the base level. 

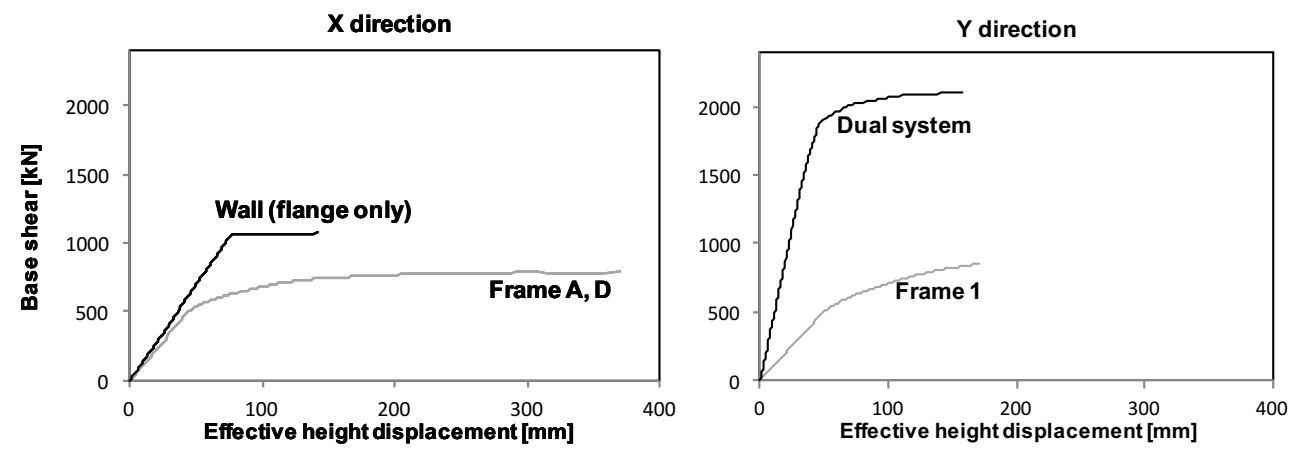

Figure 8: Pushover analyses results.
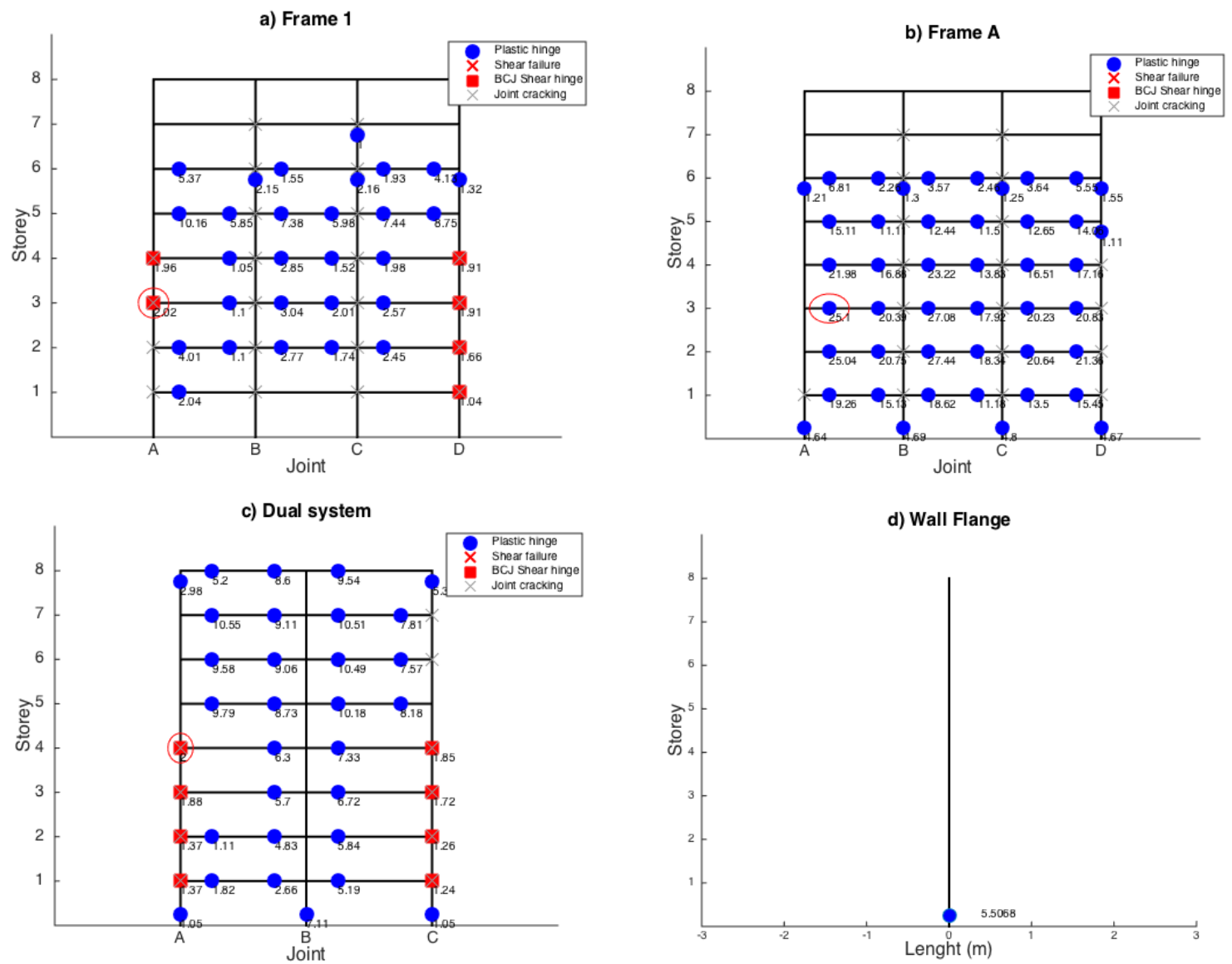

Figure 9: Plastic mechanism at ultimate limit state.

\section{COMPARISON WITH SLaMA}

For each lateral resisting systems (LRSs) individuated in Section 3, the SLaMA results are here compared with the ones of the numerical pushover analyses. The first fundamental comparison to make is based on the ability, in SLaMA, to properly capture the hierarchy of strength and, by extension, the plastic mechanism (with some degree of error). Figure 5 shows the comparison, only for frame A for brevity, of the plastic mechanism predicted with SLaMA (or, more precisely, the summary of the hierarchy of strength calculations) and the plastic mechanism extracted from the numerical analysis. As anticipated, there is high accuracy on the prediction of the hierarchy of strength in each subassembly. As an example, for the external joint D1 (indicated in Figure 5) the beam plastic hinge is predicted after the joint first shear cracking. This sequence replicates very well what is predicted in the numerical model. However, the numerical analysis indicates that the reaching of the drift capacity in the external beam at the $3^{\text {rd }}$ floor 
(highlighted in a red circle) does not allow a full redistribution of the internal actions in the frame and hence there is some discrepancy between the result of SLaMA and the numerical model in terms of plastic mechanism. This discrepancy also leads to an over estimation of the base shear capacity, with respect to the numerical analysis. This is reflected in the comparison of the SLaMA curve with the numerical one (see Figure 10.b).
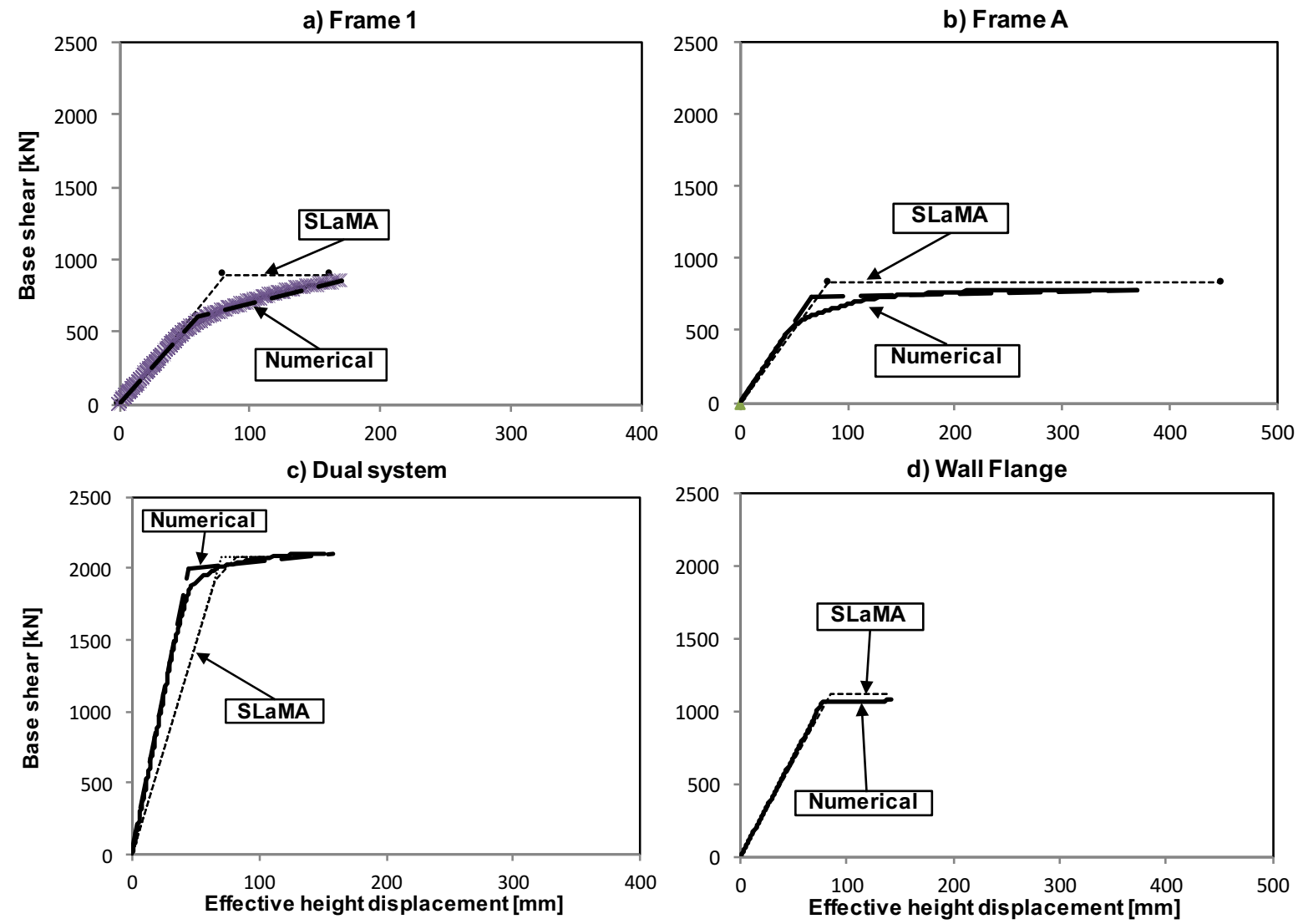

Figure 10: SLaMA vs Numerical capacity curve comparison for Frame 1, Frame A, dual system and wall.

The SLaMA-to-numerical comparison of the capacity curves is shown for all the selected lateral resisting systems in Table 1 and Figure 10, in which the bi-linear representation for the numerical curves is obtained according to ATC 1996 [26]. Satisfactory agreement is observed between the SLaMA and the numerical curves in terms of initial stiffness and ultimate strength and displacement. The main discrepancy is observed immediately after the first yielding (formation of the $1^{\text {st }}$ plastic hinge). This is attributed to the approximation, in SLaMA, for which all the structural members reach the yielding for the same structure displacement. The over prediction on the ultimate base shear is caused by the assumption for which the internal actions are fully redistributed, which is not always observed in the numerical models (see Figure 9).

In terms of quantitative SLaMA-numerical comparison (given in Table 1), it is deemed that the most important parameters to consider are the ultimate displacement and the maximum base shear. In fact, these are directly affecting the seismic performance of the structure in the Acceleration-Displacement Response Spectrum (ADRS), in the context of the DDBA. Table 1 indicates that the ultimate base shear is often over predicted by SLaMA with respect to the numerical analysis, even though the maximum error is $6 \%$. The only exception is the dual system, for which the comparison leads to almost no error. The base shear over prediction is to be attributed to the full actions redistribution hypothesis in SLaMA (see Section 4.1 and Figure 5). For what concerns the ultimate displacement, it is noted that, in this specific case, when this is 
caused by a joint (frame 1, dual system) the result is an under prediction, while when it is caused by a beam (frame A) the result is an over-prediction. This interpretation is also based on a much greater number of case studies not published yet. Since in SLaMA the yielding point base shear is assumed to be equal to the ultimate one, there is always an over-prediction for this parameter. The error is smaller for walls and dual systems, for which the wall strongly governs the behaviour. Finally, the SLaMA-numerical comparison on the yield displacement is reported for completeness but not commented because of its different definition in SLaMA and in the bi-linear numerical pushover curve.

\begin{tabular}{lcccc}
\hline \multicolumn{1}{c}{ LRS } & $\begin{array}{c}\operatorname{ERR}\left(\mathrm{d}_{\mathrm{y}}\right) \\
{[\%]}\end{array}$ & $\begin{array}{c}\operatorname{ERR}\left(\mathrm{V}_{\text {by }}\right) \\
{[\%]}\end{array}$ & $\begin{array}{c}\operatorname{ERR}\left(\mathrm{d}_{\mathrm{u}}\right) \\
{[\%]}\end{array}$ & $\begin{array}{c}\operatorname{ERR}\left(\mathrm{V}_{\mathrm{bu}}\right) \\
{[\%]}\end{array}$ \\
\hline Frame 1 & 24.6 & 31.2 & -5.0 & 2.2 \\
Frame A & -30.7 & 18.9 & 21.0 & 6.2 \\
Dual System & 58.5 & 4.4 & -16.6 & -0.7 \\
Wall flange & 10.4 & 5.8 & -4.0 & 4.0 \\
\hline
\end{tabular}

Table 1: SLaMA vs numerical discrepancy for all lateral resisting systems.

\section{CONCLUSIONS}

Four bi-dimensional lateral resisting systems of different typology (frame, cantilever wall, frame-wall dual system) were extracted from a real RC 8-storey building. Their lateral capacity, in terms of non-linear static capacity curve and plastic mechanism, was assessed by means of "by-hand" analytical predictions obtained with the Simple Lateral Mechanism Analysis (SLaMA). The results were compared with refined numerical models. The comparisons show that SLaMA is capable of reproducing the local interaction (actual hierarchy of strength) between the structural members. Moreover, the method allows to have an acceptable estimation of the plastic mechanism of the structure at the ultimate limit state (ULS) and of the lateral capacity curve. In fact, the match between the SLaMA and the numerical pushover analyses is satisfactory with a maximum discrepancy of about the $6 \%$ for the ULS base shear and $21 \%$ on the ULS displacement, for the cases analysed in this paper. It is worth mentioning that the qualitative trends outlined in this study are representative of different structural typologies and mechanisms. Nevertheless, further applications are needed to better quantify the limits of the SLaMA method and the range of the expected errors.

SLaMA is a useful tool to characterize any local/global failure mechanism characterizing the structural system which cannot be easily identified by using commercial software. The method can be employed to check the accuracy of the numerical models and to identify the main sources of errors. This allows to maintain a continuous control on the modelling procedure, improving the user confidence in the seismic assessment of the structural system. Furthermore, SLaMA allows to clearly identify the main structural weaknesses and to design proper retrofit solutions.

\section{ACKNOLEDGEMENTS}

This study was partially funded by the Italian Department of Civil Protection, in the framework of PE 2014 - 2018 joint program DPC-ReLUIS, Task RS4: “Post-earthquake analysis: usability, damages, seismic design of repair and strengthening interventions" and by the "SAFER Concrete Technology" project, funded by the New Zealand Natural Hazard Research Platform (NHRP). 


\section{REFERENCES}

[1] Uva G., Sanjust C. A., Casolo S., Mezzina M., ANTAEUS project for the regional vulnerability assessment of the current building stock in historical centers. International Journal of Architectural Heritage, 10(1), 20-43, 2016.

[2] Uva G., Porco F., Fiore A., Mezzina M., The assessment of structural concretes during construction phases. Structural Survey, 32(3), 189-208, 2014. doi:10.1108/SS-06-20130023 .

[3] Porco F., Uva G., Fiore A., Mezzina M., Assessment of concrete degradation in existing structures: a practical procedure. Structural Engineering and Mechanics, 52(4), 701-721, 2014.

[4] Porco F., Porco G., Uva G., Sangirardi M., Experimental characterization of "non- engineered" masonry systems in a highly seismic prone area. Construction and Building Materials, 48, 406-416, 2013.

[5] Fiore A., Porco F., Uva G., Effects of the yield and ultimate strengths of the equivalent strut models on the response of existing buildings with infill panels. International Journal of Structural Engineering, 6(2), 140-157, 2015.

[6] Porco F., Fiore A., Casolo S., Comparison between seismic retrofitting solutions for existing reinforced concrete buildings: a case study. International Journal of Structural Engineering, 5(3), 242-261, 2014.

[7] Calvi GM, Magenes G, Pampanin S.: Relevance of beam-column joint damage and collapse in RC frame assessment. Journal of Earthquake Engineering, 6 (Special Issue 1), 75-100, 2002.

[8] Pampanin S, Magenes G, Carr A. Modelling of Shear Hinge Mechanism in Poorly Detailed RC Beam-Column Joints. In fib Symposium “Concrete Str. in Seism. Reg.”, May 2003. Paper n. 171.

[9] Del Vecchio C, Di Ludovico M, Prota A, Manfredi G, Modelling beam-column joints and FRP strengthening in the seismic performance assessment of RC existing frames, Composite Structures, 142, 107-116, 2016.

[10] Del Vecchio C, Di Ludovico M, Balsamo A, Prota A, Manfredi G, Dolce M.: Experimental investigation of exterior RC beam-column joints retrofitted with FRP systems. ASCE Journal of Composites for Constructions, 18(4), 1-13, 2014.

[11] New Zealand Society for Earthquake Engineering, The seismic assessment of existing buildings - Technical guidelines for engineering assessments. Revised draft, 10 October 2016.

[12] Carr, A.J. "Ruaumoko Program for Inelastic Dynamic Analysis - Users Manual", Carr Research Ltd., Christchurch, New Zealand, 2009.

[13] Pampanin, S., Kam, W.Y., Akguzel, U., Tasligedik, A.S., Quintana-Gallo, P., Seismic Performance of Reinforced Concrete Buildings in the Christchurch Central Business District: Part I - overview. Natural Hazard Platform Recovery Project report. 2012a.

[14] Pampanin, S., Kam, W.Y., Akguzel, U., Tasligedik, A.S., Quintana-Gallo, P., Seismic Performance of Reinforced Concrete Buildings in the Christchurch Central Business District: Part II - damage report. Natural Hazard Platform Recovery Project report. 2012b. 
[15] Del Vecchio, C., Gentile, R., Pampanin, S., The Simple Lateral Mechanism Analysis (SLaMA) for the seismic performance assessment of a case study building damaged in the 2011 Christchurch earthquake. University of Canterbury technical report, New Zealand, 2017.

[16] Sharpe, R.D. The Seismic Response of Inelastic Structures. Ph.D. Thesis, Department of Civil Engineering, University of Canterbury, 1974.

[17] Priesley M.J.N., Calvi G.M., Kowalsky, M.J. Displacement-Based Seismic Design of Structures, IUSS Press, Pavia, Italy, 2007.

[18] Montejo, L., Kowalsky, M.J., Cumbia - set of codes for the analysis of concrete members, theory and user guide. North Carolina state university technical report. 2007.

[19] Mander, J.B., Priestley, M.J.N., Park, R., Theoretical stress strain model for confined concrete. Journal of Structural Engineering, 114, 1804 - 1826, 1988.

[20] King, D.J., Priestley, M.J.N., Park., R., Computer programs for concrete column design. University of Canterbury technical report, New Zealand, 1986.

[21] Berry, P.B., Eberhard, M.O. Practical performance model for bar buckling. ASCE Journal of structural engineering, 131(7), 2005.

[22] Kowalsky, M.J., Priestley, M.J.N. Improved analytical model for shear strength of circular reinforced concrete columns in seismic regions. ACI structural journal, 97(3), 2000.

[23] Krolicki, J., Maffei, J. and Calvi, G.M. Shear Strength of Reinforced Concrete Walls Subjected to Cyclic Loading. Journal of Earthquake Engineering, 15(1), 30-71, 2011.

[24] New Zealand Society for Earthquake Engineering, Assessment and Improvement of the Structural Performance of Buildings in Earthquakes, New Zealand, 2006.

[25] Tasligedik, A.S., Agkuzel, U., Kam, W.Y., Pampanin, S., Strength Hierarchy at Reinforced Concrete Beam-Column Joints and Global Capacity. Journal of Earthquake Engineering, 0, 1 -34, 2016.

[26] Applied Technology Council (ATC), Seismic evaluation and retrofit of concrete buildings - Volume 1. Report SSC 96-01, 1996. 